\title{
Los estudios agrarios en el Territorio Nacional del Chaco: una aproximación historiográfica $^{1}$
}

Adrián Almirón*

\section{Resumen:}

El análisis de la historia agraria del Chaco permite identificar diferentes momentos de construcción histórica. De esta forma el trabajo tiene como objetivo analizar las distintas tendencias historiográficas que pueden señalarse en la construcción de una historia agraria en el Chaco. Para este caso, tomaremos como referentes aquellas obras que dedican especial atención a la tenencia de la tierra y al proceso de colonización que se produjo en el Territorio Nacional del Chaco entre 1920 y 1950.

A partir de esto, entendemos que se construyeron tres relatos que resultaron de las tendencias y necesidades de la época. Estos relatos asimismo demuestran cómo ha evolucionado. De esta forma realizar una observación en perspectiva nos posibilita no solo conocer la evolución historiográfica de los temas tratados, sino que nos habilita a formular nuevos interrogantes para complejizar el mundo agrario del chaqueño.

Palabras Claves: Territorio-Historiografía- Chaco- Colonización-Identidad

\begin{abstract}
:
The analysis of the agrarian history of Chaco identifies different times of historical construction. This work aims at analyzing the different historiographical tendencies can be pointed in the construction of an agricultural history in the Chaco. For this case, we take as reference works that pay special attention to land tenure and the process of colonization which took place in the National Territory of the Chaco between 1920 and 1950.

Based on this, we understand that they were built three stories of the trends and needs of the time. These stories also demonstrate how it has evolved. Thus perform an observation in perspective enables us not only to know the historiographical evolution
\end{abstract}

\footnotetext{
1 Agradezco los comentarios y aportes realizados por los investigadores que han tenido la generosidad de leer este trabajo. En especial quisiera destacar los aportes y los comentarios de los investigadores Marta Ruffini, Maria Silvia Leoni y Enrique Schaller.

* Universidad Nacional del Nordeste / Argentina. E-mail: almiron.adrian84@yahoo.com.ar.

Revista Eletrônica da ANPHLAC, n.14, p. 109-131, jan./jun. 2013. http://revista.anphlac.org.br/index.php/revista
} 
of the topics, but enables us to formulate new questions to complicate the agrarian world of Chaco.

Keywords: Territory-Historiography-Chaco-Settlement-Identity

\section{El mundo agrario del Chaco desde la Historia}

Los estudios agrarios del Territorio Nacional del $\mathrm{Chaco}^{2}$ nos permiten tener una mirada amplia sobre diversos aspectos que son fundamentales para entender el proceso histórico del Chaco.

Desde las primeras obras hasta las más recientes, se evidencian diferentes análisis de la historia agraria chaqueña, como ser trabajos que tienen como objetivo describir el proceso de colonización, las formas de tenencia de la tierra, la producción agrícola y ganadera, las diversas formas de explotación, la evolución de las cooperativas, las asociaciones, los conflictos rurales. Es decir, el mundo agrario chaqueño se caracteriza por la diversidad de escenarios e intereses en pugna.

El marco temporal que hemos tomado para nuestro análisis corresponde entre 1920 y 1950, la justificación de este periodo radica en que durante estos años se acentuó la colonización del suelo fiscal, produciendo un acelerado proceso de ocupación de la tierra por colonos. Paralelo a esto convivieron dos modelos productivos primarios, por

2 El Territorio Nacional del Chaco (1862-1951) fue uno de los últimos espacios integrados al Estado Argentino. Tras la guerra del Paraguay (1864-1870), comenzó un proceso de poblamiento en estas tierras, paralelo a esto, se llevo a cabo el avance militar para dominar a las comunidades indígenas, que se encontraba viviendo en estas tierras.

En 1951, el Chaco se provinciliza por decisión del gobierno nacional, el que dictamina esta decisión fue el presidente Juan Domingo Perón. La nueva provincia pasó a llamarse Provincia Presidente Perón. Tras el golpe de Estado de 1955, comienza un proceso de revisión sobre las acciones llevadas adelante por el gobierno peronista, producto de esto, se suprime el nombre Presidente Perón y vuelve a denominarse Provincia del Chaco.

Este Territorio además forma parte de una región geográfica que supera los límites nacionales, el Gran Chaco. Está compuesta actualmente por los siguientes países: Argentina, Paraguay, Bolivia y Brasil. La dimensión que alcanza aproximadamente es de 1.200.000 Km.

Para una mejor comprensión del espacio, el Gran Chaco es dividida en tres grandes zonas:

1) El Gran Chaco Boreal, el cual se rodea la región sub-amazónica del Brasil, todo el oeste de Paraguay y buena parte del este de Bolivia.

2) El Chaco Central por su parte se inicia en el Río Pilcomayo y se extiende hasta el sur del Río Bermejo, comprendiendo de esta forma la totalidad de la provincia de Formosa y todo el noroeste de la provincia de Salta en Argentina.

3) Y finalmente el Chaco Austral, que se extiende desde la cuenca del Río Bermejo hasta el Río Paraná, comprendiendo de esta forma la provincia del Chaco y Santiago del Estero, gran parte de la provincia de Tucumán, el sureste de la provincia de Salta y el norte de la provincia de Santa Fe.

Nuestro trabajo se centra en el Chaco Austral, específicamente el Territorio Nacional del Chaco.

Revista Eletrônica da ANPHLAC, n.14, p. 109-131, jan./jun. 2013.

http://revista.anphlac.org.br/index.php/revista 
un lado la explotación forestal y por otro lado, comenzó a expandirse lentamente el cultivo algodonero.

La transformación agrícola que se produjo a partir de la explotación algodonera, originó una frontera agrícola que será útil a los objetivos económicos, políticos y sociales de la Nación. Cabe destacar que el Territorio Nacional del Chaco dependía directamente del Estado Nacional, motivo por el cual la aplicación y fomento de cultivos, junto con el asentamiento de familias para llevar adelante estas labores fueron gestionadas desde Buenos Aires.

De esta forma la política sobre el suelo fiscal será un elemento clave que tenía el Estado para consolidar una frontera agraria tendiente a ser insertada al modelo agroexportador.

Nuestra mirada se detendrá en analizar los trabajos históricos, referido a la política de tierras y la colonización del Territorio Nacional del Chaco, buscando encontrar continuidades y rupturas en las producciones realizadas, haciendo énfasis en los diversos lugares de producción que fueron consolidándose con el correr del tiempo.

El objetivo final es demostrar la heterogeneidad de resultados alcanzados desde centros regionales y nacionales, esta perspectiva que desarrollaremos nos permitirá construir una sistematización de las obras relacionadas con corrientes históricas y también con diversas líneas de interpretación de otros campos de las ciencias sociales que nos ayudan a complejizar el pasado.

\section{Las primeras Historias agrarias: La Fundación del Chaco Agrario}

En las primeras obras referidas al agro del Territorio, los distintos autores ${ }^{3}$ buscaron construir una historia local chaqueña, basándose en la biografía de los primeros pobladores que llegaron al Territorio. Estos trabajos se nutrieron en su mayor medida de experiencias vividas por los colonos; constituyendo un relato anecdótico más que histórico, destacando las vivencias de estos inmigrantes.

\footnotetext{
3 En este sentido debemos rescatar que entre 1910 y 1946 se construyo un movimiento intelectual en la ciudad de Resistencia, donde una de las preocupaciones fundamentales de estos primeros pensadores del Territorio, fue la falta de identidad en el Chaco. Entre estos primeros hombres dedicados a estos problemas destacamos las acciones de Juan Ramón Lestani, Juan de Dios Mena, Crisanto Domínguez, Gaspar Benavento, Eduardo Miranda Gallino. Para ampliar sobre este tema recomendamos el trabajo de María Silvia LEONI (1996).
}

Revista Eletrônica da ANPHLAC, n.14, p. 109-131, jan./jun. 2013. http://revista.anphlac.org.br/index.php/revista 
Estas narraciones que trataban sobre el agro chaqueño surgieron a partir de una problemática que los intelectuales de la región, definieron como la falta de identidad. Esta inquietud determinó la construcción de historias de forma asistemática, dado que la mayoría de estos escritores no tenían formación académica.

En el periodo territoriano no podemos hablar en el Chaco de la constitución de un campo historiográfico, sino de la existencia de un espacio protoespacio historiográfico. No existía el historiador profesional ni instituciones que favorecieran este desarrollo, y quienes se volcaron a la historia, en muchos casos ocasionalmente (periodistas, docentes, naturalistas, sacerdotes), la consideraron una tarea complementaria de sus otras actividades. Por otro lado, los principales historiadores correntinos Manuel F. Mantilla y Hernán F. Gómez, abordaron el pasado chaqueño en tanto se vinculaba con la historia de su provincia (LEONI, 2008, p 3)

El pequeño círculo de escritores reunidos en la "Peña de los Bagres", fue el que supo identificar un mundo rural que les daba identidad. Estos intelectuales del Territorio tenían lo que Edward Said caracterizó con una naturaleza crítica a la sociedad y una condición esencial del intelectual que denominó el espíritu amateur. En este sentido los miembros de este grupo no formaron parte de instituciones académicas, su motivación fue personal para contribuir con la sociedad, dado que lo que buscaban era definir una identidad del Territorio.

Está identidad chaqueña se construyó a partir de la mezcla de actores disimiles, por un lado indígenas, los dueños de la tierra, pero expulsados en su forma de vida; los inmigrantes que llegaron desde finales del siglo XIX, y los migrantes que arribaron desde 1920 buscando suelo para poblar y cultivar, que se asentaron en las colonias fiscales. Esta conjunción de personas hizo la idea de crisol de razas y fue una forma de explicar la identidad chaqueña.

El conjunto de las primeras obras se concentró en la figura del hombre poblador, forjador de la civilización en un contexto hostil inserto en el desierto verde. Con esta concepción surge una obra que logra sintetizar estos componentes. El autor de este trabajo fue Guido Miranda ${ }^{5}$, el cual forjo un relato fundacional, a través de un

\footnotetext{
4 "En 1936, surgía la Peña de los Bagres, producto de las reuniones informales de escritores, artistas y bohemios que se realizaban en el restorán Chanta Cuatro (...) se recitaban poemas, leían cuentos o trozos de novelas, comentaban las actividades artísticas locales e invitaban a exponer a figuras destacadas que visitaban la ciudad". LEONI María Silvia (1996, p. 9).

5 Guido Miranda nació en Vera en 1902 (Santa Fe) y falleció en Resistencia en 1994 (Chaco). En 1924 llego al Chaco y ejerció como maestro en diversas localidades. También se dedicó plenamente a la

Revista Eletrônica da ANPHLAC, n.14, p. 109-131, jan./jun. 2013.

http://revista.anphlac.org.br/index.php/revista
} 
ensayo histórico que narra el desarrollo del agro del Territorio del Chaco Tres ciclos Chaqueños en $1955^{6}$. En ese período el Chaco era una de las nuevas provincias del país. En este cambio administrativo desde 1951 se modificó el nombre original de Chaco pasándose a llamar Provincia "Presidente Perón". Esto repercutió en una pulseada entre diferentes sectores intelectuales, entre los cuales se encontraba Miranda, motivo por el cual consideró su obra Tres ciclos... como una respuesta de los sectores de los ciudadanos que no estaban de acuerdo con la convención constituyente de 1951 que le dio nombre a la nueva provincia.

Pero además de este contexto político en el cual surge la obra, la realidad del mundo agrario durante esta etapa el cultivo algodonero comenzó una etapa de lento decaimiento de dicho cultivo, esto se produjo a partir de los nuevos direccionamientos que tomó el gobierno nacional tras el derrocamiento de Perón, apostando a una economía agrícola de exportación, generando una crisis en las producciones agrarias regionales. El período algodonero estaba llegando a su fin.

En este contexto político, social y económico se inserta la obra de Miranda Tres ciclos... La particularidad de este ensayo histórico, es la periodización histórica propuesta en tres diferentes ciclos que se encuentran vinculados con la evolución agraria, social y política del Territorio, los ciclos son: "Fundación”, "Tanino" y “Algodón”. Esta periodización analiza la historia del Chaco desde finales del siglo XIX hasta su provincialización.

Este relato, sistemático y prolijo integra los distintos agentes políticos, sociales y económicos del agro chaqueño, asimismo realiza un análisis de las relaciones y los conflictos que se produjeron en la sociedad del Chaco. La narración de los diversos procesos históricos a través de los ciclos le permite a Miranda lograr construir un relato en donde no existe una secuencia cronología precisa rigiendo la trama del autor, por el contrario, el carácter de ensayo le permite a Miranda realizar avances, retrocesos y

actividad periodística, de donde destacamos su papel de redactor en el diario "La Voz del Chaco", "Estampa Chaqueña" y el Territorio, que lo cuenta hoy entre sus colaboradores permanentes. Fue secretario de la convención constituyente de 1957 y delegado interventor en el departamento de Extensión Universitaria y ampliación de estudios de la Universidad Nacional del Nordeste (UNNE) (1959-60). En: Archivo Histórico de la Provincia del Chaco. (AHPCH) El Territorio, $\mathrm{N}^{\circ}$ especial 21 de febrero de 1969, p. 2

6 Para una mayor profundización sobre el tema recomendamos el artículo de Delia T. ÁLVAREZ DE TOMMASSONE (2007).

Revista Eletrônica da ANPHLAC, n.14, p. 109-131, jan./jun. 2013.

http://revista.anphlac.org.br/index.php/revista 
superposiciones en el tiempo, Alfredo Veirave en su análisis sobre la obra de Miranda aseguro

Su temática constituye una red articulada en torno al eje de lo humano, a partir de ciertos conceptos claves cuya incidencia se percibe en el conjunto: la ocupación y administración de la tierra publica, el papel de las empresas extranjeras en las actividades económicas y la configuración social resultante del proceso colonizador (MIRANDA, 2005, p. 10)

Sin embargo este trabajo no fue el primero que se refirió al tema agrario. Antes y después de la aparición de los Tres ciclos..., se editaron cuentos y artículos que enfatizaban en la figura del colono chaqueño.

En este sentido destacamos las obras de José Pavlotzky ;Esta Tierra es Mía! (1947) y Juan Chudnovsky Dios era Verde (1965), Ramón de las Mercedes Tissera también ha contribuido en su artículo "La misión del Hombre en la Tierra" (1969) destacando el colono agricultor. Por último queremos destacar la novela realizada por Edwin A. Mac Donald El cansancio de la Tierra (1980), en la que este describió a través de la recreación de una historia familiar el auge y la caída del cultivo algodonero, el impacto que tuvo este en la constitución de las primeras familias colonas. El prologo del libro lo realizó Guido Miranda el cual puso énfasis en el aporte literario y social que representaba la elaboración de dicha obra

La difícil tarea de conciliar el texto literario con la aplicación de conceptos en una rama de extensión docente que a la vez comporta una sutil interrelación de la ciencia del suelo y el arte de vivir, ha sido empobrecida con apreciable ponderación en este libro, que tengo el gusto de prologar porque coincido con su autor, Edwin A. Mac Donald, en la necesidad de incrementar las posibilidades de comprensión general -no únicamente para los productores agrariosde la amenaza contra el porvenir de la humanidad que presenta "El cansancio de la Tierra", como reza el título, asumiendo el diagnostico quizá más perentorio de la época. (MAC DONALD, 1980, p. 5)

Pero uno de los autores que también aportó una mirada crítica y reflexionó sobre la identidad del Chaco fue Juan Ramón Lestani ${ }^{7}$, el cual a través de distintos trabajos ensayísticos destacó la vida política del Territorio y la presencia de los

\footnotetext{
7 Nació en 1904 en la ciudad de Resistencia. Fue periodista, político, intelectual del Chaco, principal exponente del movimiento cultural de la ciudad de Resistencia. Fue uno de los principales pensadores el Territorio, su formación educativa se limito a los estudios primarios. Dado sus problemas de salud y a la revolución de 1943 se alejo de la escena pública. Falleció en 1952, un año después de que el Chaco fuera provincializado, proceso por el cual no llego a participar. Para ampliar más sobre la vida de este autor destacamos el trabajo de María S. LEONI (2005).
}

Revista Eletrônica da ANPHLAC, n.14, p. 109-131, jan./jun. 2013. http://revista.anphlac.org.br/index.php/revista 
primeros pobladores, junto con los indígenas ${ }^{8}$. Las obras de Lestani influenciaron en los trabajos de Miranda en cuanto a la mirada sobre los actores y sobre la sociedad en general

Miranda retomaría las preocupaciones de Lestani: buscó desentrañar la identidad histórica y cultural del Chaco, para lo cual proporcionó una visión globalizadora del desarrollo histórico chaqueña y otorgó centralidad a los procesos socio-económicos. Su reconocimiento a la contribución de Lestani se manifiesta en unos breves trabajos que le dedicara a este autor (LEONI, 2008, p. 8).

Sin embargo, Miranda, a diferencia del resto, logró construir un relato donde supo combinar lo testimonial desde una perspectiva académica, algo que carecían las obras anteriores. Por este motivo, Tres Ciclos... nos demarca un hito en cuanto al tratamiento del agro territoriano visto desde una visión global de proceso donde el hombre se afirma en el suelo y se desarrolla plenamente.

La formación del autor se encontró influenciada por una tendencia historiográfica nacional de la época, que tuvo plena vigencia a partir de la segunda mitad del siglo XX, nos referimos a la Historia Social, y en especial la figura de José Luis Romero ${ }^{9}$ será de gran influencia en Miranda en el momento de realizar sus trabajos de análisis

Romero fue catalogado por nuestro escritor como un "hermano generacional" que brindó perennes lecciones; uno de los "sentidos profundos" de la realidad nacional que orientó sus inquietudes juveniles y moldeó su cosmovisión porque "identificaba el disconfirsmo de Ingenieros, el saber humanista de Henriquez Ureña y la solidez moral de Alfredo Palacio (ÁLVAREZ TOMMASONE 2007, p. 11).

8 Entre sus obras más importantes destacamos los realizados entre 1935 y 1940, las tres obras que tratan sobre estos problemas son: El Territorio Nacional del Chaco (Oro y Miseria) (1935), Unidad y conciencia. Aspectos morales del Chaco. Hacia la formación de la unidad Territorial (1938) y En los caminos del Chaco (Bocetos regionales) (1940).

9 José Luis Romero (Buenos Aires, 1909 - Tokio, 1977). Ensayista e historiador argentino. Considerado como uno de los grandes humanistas argentinos de mediados del siglo XX, ejerció la docencia en calidad de profesor de historia social y medieval en la Universidad de Buenos Aires, institución de la que llegó a ser rector. También fue decano de su Facultad entre 1963 y 1965 . Especializado en el estudio de la historia de la filosofía argentina y en la Baja Edad Media, también impartió clases como lector o como profesor invitado en las principales universidades hispanoamericanas y estadounidenses. Entre sus obras más sobresalientes, destacan El Estado y las facciones en la antigüedad (1938), Maquiavelo historiador (1943), La historia y la vida (1945), Las ideas políticas en la Argentina (1946) y Argentina: imágenes y perspectivas (1956). Una de sus últimas obras fue Latinoamérica, las ciudades y las ideas ( 1976). Un año después fallece en Tokio, donde participaba de una reunión de las Naciones Unidas. Biografía consultada en http://historiapolitica.com/jlr/jlromero/jlrcrono/. Visitado por última vez: Enero del 2013.

Revista Eletrônica da ANPHLAC, n.14, p. 109-131, jan./jun. 2013.

http://revista.anphlac.org.br/index.php/revista 
En cuanto a las instituciones el Territorio hacia la década del 50 no existía una institución que se dedicara a la producción histórica. Tal como lo menciona Leoni y Tommasone en esta época el Ateneo del Chaco ${ }^{10}$ y el Fogón de los Arrieros $^{11}$ fueron las instituciones de la ciudad de Resistencia que en el espacio público se dedicaron a temas culturales en donde también estaba presente la historia.

Sin embargo, estos lugares no fueron espacios de investigación. En diciembre de 1956 se crea la Universidad Nacional del Nordeste (UNNE) y a fines de 1969 y 1970 se constituye la Junta de Historia del Chaco. Por tal motivo, teniendo presente este contexto la obra de Miranda se convierte en un trabajo referente, dado el esfuerzo que realizó el autor desde lo metodológico, conectando lo testimonial y a su vez fue testigo del cambio agrario.

\section{El tiempo del agro desde la visión Geohistórica y desde el materialismo histórico}

Durante la década del setenta y ochenta los estudios regionales del país adaptaron una perspectiva para explicar los procesos con modelos macro históricos. En este sentido, la visión histórico-estructural permitió formular nuevos interrogantes, buscando explicar la formación del agro.

El tema central de investigación de estos estudios fue "el cultivo del algodón y al proceso de colonización" se buscó desentrañar a través de este enfoque el desarrollo socio-económico de la región chaqueña.

Los conceptos de territorio como espacio y de región son sumamente importantes para elaborar la construcción histórica pues las explicaciones se vincularon a partir del entorno geográfico y la dimensión histórica. Los relatos que se encuadran en este marco teórico demuestran una región es un área en constante cambio productivo, demográfico y social. De esta forma se construyen categorías de regiones, con el objetivo de poder describir y comprender el desarrollo de los distintos actores agrarios del Chaco

Los criterios y la escala escogida nos permitirán diferenciar los elementos constituyentes de esa entidad, su organización, especialización y jerarquía relativa. Luego, es preciso distinguir a

10 El Ateneo del Chaco fue creado en 1938 y estuvo presidido por Alberto Torres, tenía el objetivo de fomentar diversas manifestaciones culturales.

11 Fue fundado en 1943 como un club cultural en la casa de Aldo Boglietti, este espacio intentó recuperar el espacio de vinculación que se había creado en torno a la Peña de los Bagres.

Revista Eletrônica da ANPHLAC, n.14, p. 109-131, jan./jun. 2013.

http://revista.anphlac.org.br/index.php/revista 
ciertos agentes y prácticas que ejercen un mayor impacto sobre el crecimiento y el desarrollo de ese espacio, hacia los cuales dirigir una atención selectiva y prioritaria que evite situar en un mismo plano a todos los aspectos a considerar (VALENZUELA. 2007, p. 187).

Las explicaciones de estos estudios tuvieron dos enfoques que permitieron la construcción del cuerpo teórico que tendrá una visión estructuralista, relacionado un conjunto de variables que determinan un proceso evolutivo de la región. En este sentido se estudia en toda Latinoamérica los problemas del mundo agrario, tales como ser la estructura de la propiedad, el sistema de la tenencia de la tierra y el uso de la tecnología en la producción agrícola (GIRBAL BLACHA, 2008, p. 274).

Desde estas formulaciones teóricas, reconocemos dos tendencias que permiten la construcción del relato, nos referimos al materialismo histórico y a la visión geohistórica tendrán un papel central en la conformación del discurso histórico. La influencia de ambas corrientes fue un fenómeno que sucedió en todos los centros de investigación de Latinoamérica, el resultado de este influjo se evidencia en los trabajos producidos a partir de la década del setenta.

Además y complementando a esa mutación referida, que desplaza finalmente la hegemonía del positivismo historiográfico en Latinoamérica, para sustituirla por una situación de coexistencia de múltiples posturas historiográficas, la revolución de 1968 va a representar también, para las distintas naciones de América Latina, y en lo que corresponde a sus respectivas historiografías, la irrupción y amplia difusión de dos matrices de pensamiento social e historiográfico que son, en primer lugar el marxismo y en segundo lugar la célebre corriente de historiadores conocida bajo el equívoco nombre de "Escuela de Annales"(AGUIRRE ROJAS, 2003, p. 15).

La posición del materialismo histórico se encuentra vinculada con la Teoría de la Dependencia. Esta privilegiaba las condiciones internacionales de funcionamiento del sistema y las que jerarquizan los factores internos de acumulación. Fue elaborada por los intelectuales de países del Tercer Mundo y fue la posición antagónica de la Teoría de la Modernización $^{12}$ sobre el desarrollo de las sociedades de primer mundo.

12 Galaffasi sostiene por la teoría de la modernización: La modernización implica una visión bastante etnócentrica, pues la regla debía ser abandonar las pautas culturales y sociales "atrasadas" existentes en las áreas subdesarrolladas para adoptar aquellas "claramente modernas" existentes en los países desarrollados. Esta teoría de la modernización, desarrollada por un nutrido grupo de intelectuales fundamentalmente Estados Unidos asumía que los cambios unilineales y que, por tanto, las sociedades menos desarrolladas han de seguir el mismo camino que ya han recorrido las sociedades desarrolladas". (GALAFASSI, 2004, p 344).

Revista Eletrônica da ANPHLAC, n.14, p. 109-131, jan./jun. 2013.

http://revista.anphlac.org.br/index.php/revista 
Explicar la evolución social y económica de las regiones consideradas marginales fue una preocupación de distintas organizaciones estatales y académicas nacionales e internacionales. Mediante esta preocupación se abrieron debates en torno al desarrollo productivo de la región, desde la perspectiva de crítica de la teoría de la dependencia.

Una de las organizaciones nacionales representativas que demuestra el espíritu de esta época de debates en torno al desarrollo regional fue el Consejo Federal de Inversiones (CFI). Este fue creado en 1959 con la idea de fomentar el desarrollo productivo de las distintas regiones Argentinas. Para ello esta organización promovió y aun continúa emprendiendo investigaciones en las distintas regiones del país. Uno de los trabajos de indagación fue realizado por Daniel Slutzky. Fue publicado en 1974 con él titulo Tenencia y distribución de la tierra en la Región NEA. El aporte que realiza esta obra es vincular la conformación de la sociedad desde la génesis de la producción agrícola hasta el momento álgido en donde se evidenciaban claramente diferencias sustanciales en cuanto a la acumulación de riquezas en la región.

Tiempo después se editará en colaboración con Víctor Brodersohn y Cristina Valenzuela una nueva obra que amplía el marco conceptual, con el titulo Dependencia interna y desarrollo: el caso del Chaco (2009).

Estos trabajos se encuentran enfocados desde el materialismo histórico y la geografía crítica ${ }^{13}$ y plantean la conformación del agro chaqueño a partir del desarrollo capitalista nacional e internacional. El trabajo realizado por Slutzky permite establecer un proceso de evolución en cuanto a la tenencia de la tierra, a las formas de explotación y las distintas organizaciones que se establecieron en el Chaco.

Por su parte la obra titulada Dependencia Interna... tiene como aporte la realización de una periodización donde se acentúa el análisis desde la corriente historiográfica materialista

La evolución socio-económica del Chaco muestra una singular sensibilidad hacia las modalidades dominantes de desarrollo nacional. $\mathrm{Si}$ se considera los principales esquemas que orientaron la evolución del país, habrá que observar que el Chaco estaba incorporado y

\footnotetext{
13 "La geografía critica, desde su concepción del espacio como un producto social resultante de las innumerables interacciones inherentes en la acción del Capitalismo a escala global, regional y local, explora la dialéctica de las relaciones económicas asimétricas, el intercambio dispar y los procesos de desarrollo desigual, identificando la dinámica de inserción y fragmentación de los espacios, redes y flujos, como formas de interrelaciones múltiples" (VALENZUELA, 2007, p 189).
}

Revista Eletrônica da ANPHLAC, n.14, p. 109-131, jan./jun. 2013.

http://revista.anphlac.org.br/index.php/revista 
participaba de tales modalidades o esquemas del desarrolla nacional (BRODERSOHN, SLUZTKY, VALENZUELA. 2009, p. 23).

Los autores entienden que la historia agraria del Chaco atravesó tres grandes etapas: 1. Incorporación del Chaco al esquema nacional primario-exportador; 2. La ampliación del mercado interno y el papel dominante de la economía algodonera; y 3. Redefinición de la inserción productiva chaqueña en el sistema nacional: diversificación agropecuaria y complementación con la región Pampeana. La periodización propuesta por los autores se encuentra emparentada con la idea de ciclos descritos por Miranda, no obstante el tratamiento de fuentes y la utilización de datos estadísticos, complementa la obra de Tres ciclos... Desde el plano de las relaciones sociales el trabajo de Brodersohn, Slutzky y Valenzuela realiza un gran aporte en el análisis histórico del campo chaqueño, la formación de una pequeña burguesía”. Este tendrá un papel preponderante en el desarrollo de la agricultura chaqueña, a partir de la década del sesenta. La génesis de este grupo, de acuerdo a los autores se encuentra en la década del treinta. Tal como lo plantean una de las características de la colonización del Chaco, fue el asentamiento de productores intrusos ${ }^{14}$ que no poseían capital, los cuales tenían una superficie que no superaba las 50 hectáreas, por el contrario, este pequeño grupo en el momento de asentarse en las tierras fiscales traían consigo capitales y en general pudieron obtener entre 50 hasta 100 hectáreas para la producción. Esto determinó que pudiera con el tiempo capitalizarse. Desde la década del sesenta, este grupo tendrá mayores ventajas de poder continuar en el campo chaqueño

(...) En todo el periodo algodonero, las distintas medidas implementadas por el poder central tuvieron efectivamente un alcance provincial, es decir beneficiaron a la casi totalidad de los sectores sociales locales. A partir de la década de 1960 el accionar del Estado se orienta a promover los cultivos de exportación y en esa medida los destinatarios de su accionar son, fundamentalmente, los sectores sociales que estaban en condiciones de diversificar y modernizar sus establecimientos (...) (BRODERSOHN, SLUZTKY, VALENZUELA, 2009, p. 39).

Este análisis sobre la formación de una pequeña burguesía fue atendida también por Nicolás Iñigo Carrera en sus trabajos La estructura de la región algodonera Chaqueña, su génesis y un análisis particularizado de la situación de conflicto. Las

14 De acuerdo a la Dirección General de Tierras, organismo encargado de llevar adelante la colonización de los Territorios Nacionales, era considerado intruso todo aquel que se asentaba sin tener permiso previo de este organismo. Transformándose en un ocupante de hecho.

Revista Eletrônica da ANPHLAC, n.14, p. 109-131, jan./jun. 2013.

http://revista.anphlac.org.br/index.php/revista 
Huelgas de 1934 y 1936 y Movimiento social y alianza de obreros y campesinos. Chaco (1934-1936), este último en colaboración con Jorge Podestá, donde exponía un conflicto social que tenía como protagonistas a los colonos algodoneros. A partir de este concepto explica de forma sintética y a través de un marco teórico materialista los distintos fenómenos sociales y políticos que ocurrieron en torno a la estructura productiva algodonera. ${ }^{15}$

Asimismo bajo esta misma corriente histórica, Jorge Rozé estudió el conflicto algodonero y las políticas de tierras durante la provincia en su libro Lucha de clases en el Chaco Contemporáneo (2007), el autor plantea el estudio de los distintos conflictos agrarios como una continuidad de la lucha de clases ${ }^{16}$. En conjunto los aportes de esta línea de interpretación de la sociología con una base histórica y económica, se complementan con investigaciones de orden nacional que integran de manera global las estructuras socioeconómicas regionales del país. ${ }^{17}$ Alejandro Rofman y Guido Galaffasi son autores que contribuyeron al análisis de estas regiones, sus trabajos plantean de forma indirecta que la regionalidad es un recorte espacial diferendo producto de la reproducción social y la acumulación capitalista. Por este motivo las regiones resultantes tienen un área de extensión cambiante, definida por su historia y su función en los marcos sociopolíticos y económicos específicos.

Por otra parte, el segundo enfoque estructural que permitió una nueva aproximación a las características del agrarismo chaqueño fue la visión Geohistórica. El padre de este pensamiento fue Fernando Braudel (1902-1985) discípulo de Lucien Febvre (1878-1956) y su sucesor de la dirección de la revista de Annales. Su gran aporte

15 Destacamos algunas obras interesantes referidas al proceso de colonización del Chaco: Nicolás Iñigo CARRERA, "Indígenas y fronteras. Campañas militares y clase obrera. Chaco (1870-1930), La violencia como potencia económica: Chaco 1870-1940; El papel del Estado en un proceso de creación de condiciones para la constitución de un sistema productivo rural.

16 El autor sostiene en los fundamentos del trabajo: "Postulamos que el conflicto que se expresa de distintas formas en el Chaco desde ya hace cuatro décadas, es una crisis en la que las relaciones de producción no se corresponden con el desarrollo de la fuerzas productivas, agravadas por fenómenos que adquirieron su expresión en cambios de la naturaleza (...)" (ROZE, 2007, p. 20).

17 Alejando B. ROFMAN y Luis A. ROMERO sostienen lo siguiente: "Las decisiones adoptadas dentro del sistema económico-social y que se vinculan con la formación de las regiones no se refieren a leyes especificas de funcionamiento de dicho sistema, sino que responden a factores de atracción o movilización de los procesos vocacionales que actúan aislados de todo otro contexto de orden superior" (1997, p 15).

Asimismo, ROFMAN ha realizado numerosos trabajos bajo esta perspectiva de análisis: Economías regionales: Diagnostico y propuestas..., Políticas alternativas de transformación en el medio rural minifundista, Las economías del interior: una estrategia para enfrentar la crisis, entre otros títulos que tratan sobre la misma temática.

Revista Eletrônica da ANPHLAC, n.14, p. 109-131, jan./jun. 2013.

http://revista.anphlac.org.br/index.php/revista 
fue a través de su obra El Mediterráneo y el mundo Mediterráneo en la época de Felipe II (1949) donde plantea que el espacio natural es el escenario en donde se desarrollan los intercambios y los conflictos entre las civilizaciones.

Sumada a este enfoque histórico se agrega otra teoría académica que influye notablemente en la formación de estas producciones, nos referimos a la "síntesis geográfica”. Esta entiende que la geografía debe descubrir y definir la personalidad regional, que se funda en la específica combinación de los diversos elementos integrantes del paisaje.

Estos dos enfoques permitieron conformar trabajos de investigación en donde lo agrario será representado en forma histórica mediante la transformación del espacio geográfico.

En la provincia del Chaco un paso fundamental fue la creación de la Universidad Nacional del Nordeste (UNNE) y del Instituto de Investigaciones Geohistóricas $(\mathrm{IIGHI})^{18}$, ambos fueron los lugares de producción que detentaron el capital científico $^{19}$, donde los historiadores, los geógrafos y los sociólogos llevaron adelante las investigaciones agrarias de la región. ${ }^{20}$

Estas nuevas interpretaciones permitieron la profundización de las particularidades locales, articulando las variables económicas con las del campo social y político, buscando de esta forma, continuar la línea historiográfica fundacional.

Uno de los primeros trabajos que nos ofrece esta interpretación fue realizada por Enrique Bruniard con su obra El gran Chaco Argentino (ensayo de interpretación geográfica) (1978), la publicación estaba dedicada al centenario de la colonización del Chaco. En su nota preliminar el autor aclara el trabajo clásico de Tres Ciclos... fue

\footnotetext{
18 Fue creado en marzo de 1979 en la ciudad de Corrientes y desde 1983 su sede se encuentra en Resistencia, Chaco, lo que le permite un mayor contacto e intercambio con la UNNE. En 1975 Ernesto Meader inicio la publicación de la Folia Histórica Nordeste.

19 El autor define a campo Científico "como sistema de las relaciones objetivas entre las posiciones adquiridas (en luchas anteriores) es el lugar (es decir, el espacio de juego) de una lucha de concurrencia, que tiene por apuesta como capacidad técnica y como poder social, o, si se prefiere, el monopolio de la competencia científica, entendida en el sentido de capacidad de hablar y de actuar legítimamente (es decir, de manera autorizada y con anterioridad) en materia de ciencia, que esta socialmente reconocida a un agente determinado" (BOURDIEU, 1999. p. 76).

20 En su introducción a la "Historia del Agro Argentino", Barsky y Gelman, plantean "a medida que avanzamos en el tiempo, y especialmente en el siglo XIX, los historiadores se ocuparon en buena menos de los problemas de la historia agraria. En buena medida esa falta fue corregida por otros científicos sociales, economistas, sociólogos, antropólogos y también ingenieros agrónomos" (BARSKY y GELMAN, 2009, p. 20).
}

Revista Eletrônica da ANPHLAC, n.14, p. 109-131, jan./jun. 2013.

http://revista.anphlac.org.br/index.php/revista 
consultado en el momento de la realización de la investigación. Asimismo la obra tiene el objetivo de

El sujeto de estudio plantea la problemática regional del gran Chaco y especialmente de la Provincia del Chaco, en cuanto las condiciones naturales y el proceso histórico de su desarrollo se inscriben en aquella estructura espacial, más amplia, en la que residen y se combinan los elementos que le otorgan verdadera significación a cada una de las partes; y también considerando que ha sido esta provincia la que ha animado la vida de la región con mayor rigor y entusiasmo (BRUNIARD, 1978, p. 5).

Esta fue la primera gran obra geohistórica de la región, convirtiéndose en un clásico y en una obra de consulta constante para las investigaciones sobre el Chaco. Bajo esta misma línea de interpretación, tiempo después se publica la obra de Héctor Borrini La Colonización como Fundamento de la organización Territorial del Chaco (1930-1953” (1987). La monografía estudia la colonización del Chaco como un proceso que vincula distintas etapas de control y desarrollo de la región que son propicias para fomentar la agricultura chaqueña.

(...) Entendemos como colonización no solo el mero hecho de habitar tierras "incultas", sino además el control conveniente de la distribución de la tierra, proveer al colono de los medios indispensables para realizar su cometido, tender la infraestructura necesaria para la fluida producción y comercialización, y orientar las actividades concretas, podemos establecer una analogía entre ese concepto y los de ocupación y organización del espacio, en un sentido amplio y general. Es por ello que para una comprensión integral del proceso referirnos a el siguiendo una evolución propia que tuvo la colonización agropecuaria del Territorio (BORRINI, 1987, p. 91).

Desde este enfoque geohistórico el desarrollo agropecuario del Chaco fue producto de cuatro pilares fundamentales ${ }^{21}$ : la colonización ${ }^{22}$, las vías de comunicación, la producción ${ }^{23}$ y la población ${ }^{24}$.

\footnotetext{
21 "La colonización principalmente la agrícola, promovió en su actividad multiplicadora un alto crecimiento demográfico, una producción en progresivo aumento, y una organización del espacio en zonas o subregiones de mayo o menor dinámica" (BORRINI, 1987, p. 90).

${ }^{22}$ En cuanto a la colonización del suelo del Chaco destacamos los siguientes trabajos: Enrique SCHALLER (1999) e SCHALLER y BORRINI (1997).

${ }^{23}$ En cuanto a los estudios productivos del Territorio Nacional del Chaco destacamos los trabajos de Juan Carlos Larramendy y Luis A. Pellegrino El algodón ¿una oportunidad perdida?, Jurguen Bunstorf, El papel de la industria taninera y de la economía agropecuaria en la ocasión del espacio chaqueño; y Úrsula I. Nedderman, Evolución de la Actividad ganadera en el Chaco entre 1900 y 1950.

${ }^{24}$ Las obras que se destacan desde este enfoque son de los autores: Hugo H. Beck, Inmigrantes europeos en el Chaco. Transición del pluralismo al crisol; Lilia J. Osuna, El Chaco y su población (18951970); Ernesto Maeder, Población e inmigración en la Argentina entre 1880 y 1910; y Omar Zenoff, Memoria de las Breñas y su gente. Desde los orígenes hasta 1939.
}

Revista Eletrônica da ANPHLAC, n.14, p. 109-131, jan./jun. 2013.

http://revista.anphlac.org.br/index.php/revista 
La integración de estos aspectos permite entender el desarrollo agropecuario de manera global, la aplicación de la síntesis geográfica le brindó las herramientas conceptuales a Borrini para explicar la relación total en la superficie de la tierra.

Asimismo en esta misma línea de investigación, pero acentuando la historia local, subrayamos la obra de Omar Jacob Castelli. Historia de la localidad, colonias y parajes, en el ámbito del Noroeste Chaqueño (1928-1995) (2005). Su trabajo logra analizar la ocupación del Noroeste espacio chaqueño, sintetizando la historia de la ocupación junto con las características del ámbito natural en la cual se desenvuelve esta historia. Sin embargo este tipo de obra, si bien destaca de forma pormenorizada los distintos sucesos que ocurrieron en Castelli y en las colonias aledañas, no es una mera historia de pueblo, por el contrario el marco espacial que le da el autor y el enfoque que le asigna el mismo, logra superar lo local, dado que no olvida el nivel macro.

De esta forma, estas dos interpretaciones historiográficas en torno a lo agrario contribuyeron de forma valiosa a la construcción de una historia Territoriana para la sociedad chaqueña.

\section{Nuevas aproximaciones al Agro del Territorio del Chaco}

Tras la caída de los grandes paradigmas y la revisión de lo producido, las nuevas líneas de investigación tendieron a concentrarse en casos particulares para indagar y construir nuevos relatos históricos. Este tipo de investigaciones demuestran lo que Lawrence Stone denomino "el retorno de la narrativa", pues los intereses se concentraron en temáticas políticos y culturales. Girbal Blacha ha logrado sintetizar un relato homogéneo de estas nuevas interpretaciones de la historia agraria, sobre todo atendiendo a fronteras extra pampeanas las cuales han sido motivo de constantes análisis, la autora destaca

Hoy, la historia agraria regional necesita -una vez más- hacerse eco de los cambios teórico-metodológicos y conceptuales definidos, entendiendo que su tratamiento no puede hacerse exclusivamente desde un solo ángulo de observación, sea éste económico, social, político, cultural o institucional. Su estudio debe, necesariamente, compendiar todos esos aspectos, poniendo el acento en el estudio de casos particulares, que den sentido a la micro-historia para explicar los procesos macro-históricos del complejo mundo rural argentino (GIRBAL BLACHA, 2010, p. 9).

Revista Eletrônica da ANPHLAC, n.14, p. 109-131, jan./jun. 2013. http://revista.anphlac.org.br/index.php/revista 
Desde la década de los noventa distintos trabajos se han ocupado de la evolución agraria del Chaco. ${ }^{25}$ La gran variedad de temas que surgen a partir de esta nueva mirada al agro del Chaco diversifica asimismo las conclusiones estructurales.

En esta nueva revisión del mundo agrario se parten de los temas que fueron de poco interés a las construcciones históricas anteriores. El retorno del relato político en los estudios agrarios, junto con el análisis del comportamiento social y económico demuestra un intento por superar y ampliar el conjunto de las conclusiones arribadas.

El intento por comprender los diversos y variados aspectos de la cuestión rural implica alejarse de cualquier forma de interpretación unilineal y homogénea de los fenómenos que la componen. El carácter procesual de los fenómenos históricos, para resaltar los cambios y las continuidades, permite trazar conexiones entre los fenómenos y dirimir, de esta manera, los niveles y grados de importancia que pueden asumir los factores y variables que intervienen en cada caso; sin perder de vista la conexión con el conjunto, pero admitiendo las particularidades distintas y singulares (GALAFASSI, 2004, p. 11).

El común denominador del conjunto de las obras que se han publicado a partir de la década del noventa fue demostrar las rupturas y continuidades en el agro chaqueño y argentino. Con ello se ha pretendido lograr no solo fortalecer viejas tesis estructuralistas sino también se ha contribuido a la explicación de forma pormenorizada de los procesos, de esta forma se analiza a lo rural como una construcción social que está sujeta a cambios.

La obra compilada por Oscar Mari, Graciela Mateo y Cristina Valenzuela Territorio, poder e identidad en el Agro Argentino" (2010) ${ }^{26}$ nos demuestra este nuevo interés por parte de los investigadores dedicados a los estudios del agro, por aportar nuevos interrogantes y nuevas líneas de investigación, donde se destacan los trabajos

\footnotetext{
25 Es importante destacar el análisis realizado desde la Universidad de Misiones en cuanto a historia agraria del Nordeste. El Territorio Nacional de Misiones compartió características similares al Chaco, el cual puede ser entendido de forma homogénea bajo los mismos puntos de análisis. En este sentido se destacan los autores Leopoldo Bartolomé y Gabriela Schiavone. Estos dos referentes dirigen equipos de investigación para analizar la estructura agraria misionera desde un enfoque histórico-antropológico. En estos últimos años se han editado dos obras que nos posibilitan reconstruir una mirada del agro misionero que nos posibilita preguntarnos sobre lo similar y lo diferente al agro chaqueño en cuanto a población, comportamiento social de los colonos, formas de producción. Las obras son Desarrollo y estudios rurales en Misiones (2008) y Campesinos y agricultores familiares. La cuestión agraria en Misiones a fines del Siglo XX (2008).

${ }^{26}$ Los trabajos referidos al Territorio del Chaco en esta obra son los de los autores: Leandro Moglia "Poder público y cooperativismo agrícola en el Territorio Nacional del Chaco" y María S. Leoni "Representaciones del agro chaqueño: la fiesta Nacional del algodón en el Territorio Nacional del Chaco $1944 "$
}

Revista Eletrônica da ANPHLAC, n.14, p. 109-131, jan./jun. 2013. http://revista.anphlac.org.br/index.php/revista 
que estudian al poder, la conformación de los procesos de identidad que construyen los distintos agentes sociales del territorio, las relaciones interétnicas y nuevas interpretaciones que vinculan la historia ecológica con los procesos agrarios y políticos del Chaco.

Uno de los nuevos temas dentro del conjunto de obras es el medio ambiente. Entre los investigadores que ha dedicado su atención al mundo ecológico del Chaco fue Adrian Zarrilli, atendiendo específicamente a la explotación de los bosques ${ }^{27}$. Asimismo el trabajo de Eduardo Rozenvaig Etnias y arboles. Historia del Universo ecológico Gran Chaco (2010), es un ensayo donde se demuestra una preocupación valiosa por la ecología chaqueña frente al modelo productivo nacional.

Por su parte los trabajos de compilación realizado por José Muzlera, Mariana Poggi y Ximena Carreras Doalla Aportes, sujetos y miradas del conflicto agrario Argentino (1910-2010)” (2011) y la compilación realizada por Juan Manuel Lerda y Luciana Liete Conflictividad en el Agro Argentino. Ambiente, Sociedad y Estado (2011) se plantean nuevas interpretaciones sobre el mundo agrario, problematizando con diversos estudios de casos la realidad del agro Argentino. En el caso específico del Chaco ambas compilaciones tienen trabajos que demuestran un interés por vincular las decisiones políticas nacionales a la producción agrícola algodonera, logrando identificar a partir de esta relación conflictos entre los distintos productores algodoneros del Chaco.

En este sentido, en las producciones más recientes se evidencia que se ha dejado de discutir el proceso de la colonización en los Territorios Nacionales y la cuestión de la tierra publica, no obstante el problema del suelo fiscal y la cuestión agraria continua siendo tratado para lograr abordar nuevas conclusiones. Podemos mencionar dos obras que demuestran nuevas perspectivas en cuanto al abordaje de estos temas, por un lado queremos destacar los trabajos compilados por Osvaldo Graciano y Violeta Gutiérrez El agro en cuestión: discursos, políticas y corporaciones en la Argentina:1870-2000 (2006), y el de Graciela Blanco y Guillermo Banzato La cuestión de la tierra publica en Argentina a 90 años de la obra de Miguel Ángel Carcano (2009), ambos estudios

27 Destacamos los siguientes trabajos: Transformación ecológica y precariedad económica en una economía marginal. El Gran Chaco argentino, 1890-1950 y Bosques vs agricultura. Una mirada a los limites históricos de sustentabilidad de los bosques argentinos en un contexto de la explotación capitalista.

Revista Eletrônica da ANPHLAC, n.14, p. 109-131, jan./jun. 2013.

http://revista.anphlac.org.br/index.php/revista 
dejan en claro que los estudios de caso permiten problematizar realidades sociales y económicas vinculadas estrechamente con la política.

En relación a la política de tierras y colonización de los Territorios Nacionales, la última obra de compilación señalada, se encuentra publicado el capítulo titulado "La política de tierras en los Territorios nacionales: entre la norma y la práctica" elaborado por Susana Bandieri y Graciela Blanco, en este caso las autoras estudian la política de tierras haciendo énfasis en Patagonia, no obstante también analiza de forma superficial a los Territorios del Norte. Lo interesante de este trabajo son los resultados demostrados a partir de la comparación de la obra clásica de Miguel Ángel Cárcano Evolución Histórica del Régimen de la Tierra publica.1810-1916 y la Memoria de la Dirección General de Tierras de 1922-1928" realizada por Melitón Díaz de Vivar y aunque temporalmente aborda desde la conformación de los Territorios Nacionales hasta 1930, los objetivos de trabajo y la necesidad de continuar abordando estos temas para profundizar los estudios referidos al agro, vinculando el proceso de colonización, demandan nuevas vinculaciones históricas en los estudios sobre el agro del Chaco

(...) abordar el estudio de los mecanismos dispuestos por los distintos gobiernos para la distribución de las tierras públicas ganadas al indio, donde el Estado cumplió, sin duda, un rol decisivo. O sea, el conocimiento de las políticas y de las decisiones derivadas de esas políticas plasmadas en la legislación, resulta un árido pero indispensable camino a recorrer. Se impone entonces una aproximación a los resultados de su aplicación en los Territorios Nacionales (...) a los efectos de poder avanzar en la definición de los sujetos vinculados a esos procesos y sus relaciones con la trama social en la que se insertan (BANDIERI y BLANCO, 2009, pp. 164-165).

Desde esta perspectiva, estudiar al Estado personalizando las decisiones y los objetivos de las políticas de Estado se presentan como los nuevos análisis para comprender las decisiones realizadas en la sociedad (BOHOSLAVSKY y SOPRANO, 2010 , p. 24) ${ }^{28}$. El trabajo de Noemí Girbal-Blacha en torno a estas preocupaciones plantea una visión integral sobre las políticas públicas en el Gran Chaco Argentino,

28 Cabe destacar que el Centro de Estudios de la Argentina Rural de la Universidad Nacional de Quilmes (CEAR-UNQ) ha dedicado especial atención a estos procesos. Queremos destacar el trabajo de compilación realizado por Adrian Zarrilli referido a los técnicos y los intelectuales del mundo agrario, el libro se titula Clásicos del mundo rural Argentino. Relectura y análisis de textos (2007). No obstante este centro de investigación ha producido una gran cantidad y variedad de producciones que han enriquecido el conocimiento histórico del mundo agrario. Destacamos el siguiente link en donde se puede consultar un catalogo de obras producida por el CEAR: http://ppct.caicyt.gov.ar/files/docs/catalogo-cear-2012.pdf . Visitado por última vez: Enero del 2013.

Revista Eletrônica da ANPHLAC, n.14, p. 109-131, jan./jun. 2013.

http://revista.anphlac.org.br/index.php/revista 
centralizándose en el Territorio del Chaco, Vivir en los márgenes Estado, políticas públicas y conflictos sociales. El gran Chaco Argentino en la primera mitad del Siglo $X X$ (2011). Aunque no dedica especial atención a la colonización del Chaco y al problema de la tierra, presenta consideraciones teóricas referidas a las políticas públicas realizadas en el Chaco que nos pueden ayudar a contextualizar los estudios agrarios sobre políticas de tierras.

El conjunto de estas nuevas tendencias de investigaciones nos permite afirmar que existen aun temas sin tratar, necesarios de ser vinculados desde lo micro a lo macro para poder consolidar de manera científica la historia del mundo agrario del Chaco.

\section{Consideraciones Finales}

La evolución del agro del Territorio Nacional del Chaco ha sido abordada desde diversas perspectivas, construyéndose distintos relatos. En este sentido, podemos destacar tres enfoques. Los análisis desde una perspectiva sociológica o geográfica con un fundamento histórico estuvieron constreñidos a las tendencias y motivaciones de la época, no obstante la particularidad de cada una de las obras realizadas, nos permite aproximarnos a un mundo rural complejo y heterogéneo.

Desde estas tres construcciones sobre el agro,_se evidencia una continuidad de abordar la forma de evolucionar el conjunto de la sociedad territoriana.

La primera gran narrativa la denominamos "etapa fundacional", priman las visiones de los protagonistas y de los testigos intelectuales de la época quienes con sus memorias, cuentos y artículos periodísticos describieron el agro del Territorio destacando la figura del colono como promotor del desarrollo agrícola. Dadas las condiciones de formación académica de los autores los trabajos elaborados se orientan al género ensayístico en esta primera etapa, destacamos dos hombres.

El primero de ellos es Juan Ramón Lestani, autodidacta e intelectual preocupado por la vida política del Territorio, esbozó que ponen de manifiesto un esfuerzo por explicar los hechos de los cuales el también es protagonista. Sin embargo, el autor que pudo resolver una secuenciación histórica chaqueña fue Guido Miranda, a través de los ciclos chaqueños que destacan las características sociales y económicas del Territorio.

La segunda gran narrativa que permite reconstruir un relato histórico ocurre a partir de la década del sesenta, dando trabajos que tenían como objetivo describir los

Revista Eletrônica da ANPHLAC, n.14, p. 109-131, jan./jun. 2013. http://revista.anphlac.org.br/index.php/revista 
procesos sociales en base a perspectivas estructurales, en este caso el materialismo histórico y el enfoque geohistórico posibilitaron abordar con más precisión los procesos históricos. Asimismo fueron importantes, en esta etapa la formación de academias y organismos estatales que promovieron la investigación científica desde diferentes posiciones ideológicas. El CFI financió una de las investigaciones más importantes de la región hasta el presente en materia de análisis sobre la tierra y la colonización, por otra parte el IIGHI fue el lugar de producción referente de la región del Nordeste que convoco a historiadores y geógrafos a construir un relato científico desde la unión de estas dos ciencias, la mirada sobre la historia social y la síntesis Geográfica francesa generó construcciones valiosas para la Universidad Nacional del Nordeste y para la sociedad en general, construyendo un pasado histórico fundamental para la identidad del Chaco.

Estas producciones han contribuido de forma esencial en la construcción histórica, pues significó la superación de una mirada reduccionista y local de la historia agraria. Su forma de interpretar el agro a partir de procesos económicos y sociales perdura en algunas investigaciones actuales.

Y por último reconocemos un tercer momento, donde evidenciamos una revisión de estos modelos de explicación a partir de estudios de casos, poniendo énfasis en los procesos culturales y políticos. Generando con sus conclusiones nuevos espacios de investigación desde donde abordar el agro del Territorio Nacional del Chaco. Se destacan en este caso los grupos de investigación financiados por el Consejo Nacional de Investigaciones Científicas y Técnicas (CONICET) desde diferentes universidades, los cuales trabajan con una perspectiva del agro heterogénea, representan al mundo agrario como diverso y desde allí fomentan sus trabajos, destacándose nuevos temas para analizar el desarrollo del mundo agrario chaqueño.

De esta forma la literatura sobre el agro chaqueño Territoriano aun no deja de agotarse, dado que surgen nuevas preguntas, dado que es el mismo presente el que fomenta estas premisas, la única forma de abordarlas es a través de la historia, siendo el mundo agrario, en este caso, nuestro laboratorio para encontrar respuestas.

\section{Referencias bibliográficas:}

Revista Eletrônica da ANPHLAC, n.14, p. 109-131, jan./jun. 2013. http://revista.anphlac.org.br/index.php/revista 
ACHE ACHE, Daniel Benjamín. La síntesis en geografía. Terra Nueva Etapa, Universidad Central de Venezuela, Vol. XXVI, n. 40, julio-diciembre, 2010, pp. 71-98. Colgado en línea: http://redalyc.uaemex.mx/redalyc/pdf/721/72116276004.pdf. Visitado por última vez: Enero 2013

AGUIRRE ROJAS, Carlos A. Balance crítico del siglo XX histórico. ¿Breve, largo o muy largo siglo XX?, Historia Agenda, México, CCH/UNAM, Año I//Nueva Época//n. 3, noviembre-diciembre de 2003. . Colgado en línea: http://www.cch.unam.mx/historiagenda/3/contenido/st1.htm. Visitado por última vez: Enero 2013.

ÁLVAREZ DE TOMMASSONE, Delia T. Las corrientes historiográficas y la primera historiografía chaqueña: el caso Guido Miranda. Interpretaciones. Revistas de Historiografía Argentina, n. 2. Primer Semestre de 2007. Colgado en línea: http://www.historiografia-arg.org.ar/numero\%202/Articulo\%20Tomasone.pdf. Visitado por última vez: abril 2012.

BANDIERI, Susana; BLANCO, Graciela; BLANCO, Mónica (coordinadoras). La escalas de la historia comparada. Tomo 2: Empresas y empresarios. La cuestión regional. Buenos Aires: Miño y Dávila, 2008.

BARSKY, Osvaldo y GELMAN, Jorge. Historia del agro argentino: desde la Conquista hasta comienzos del siglo XXI. Buenos Aires: Sudamericana, 2009.

BOURDIEU, Pierre. Intelectuales, política y poder. Buenos Aires: Eudeba, 1999.

BORRINI, Héctor La colonización como fundamento de la organización Territorial del Chaco (1930-1953). Cuadernos de Geohistória Regional, $\mathrm{n}^{\circ} 19$, Instituto de investigaciones Geohistoricas, CONICET-FUNDANORD, Resistencia, 1987.

BRODERSOHN, Víctor.; SLUTZKY Daniel; VALENZUELA, Cristina Ofelia. Dependencia interna y desarrollo: el caso del Chaco. Resistencia: Librería la Paz, 2009 FERNANDEZ, Sandra. Más allá del Territorio: la historia regional y local como problema. Discusiones, balances y proyecciones. Rosario: Prohistoria Ediciones, 2007. HORA, Roy. Dos décadas de historiografía argentina. Punto de Vista, Buenos Aires, n. 69, 2001.

GALAFASSI, Guido (compilador). El campo diverso. Enfoques y perspectivas de la Argentina Agraria del Siglo XX. Bernal: Universidad Nacional de Quilmes, 2004.

Revista Eletrônica da ANPHLAC, n.14, p. 109-131, jan./jun. 2013. http://revista.anphlac.org.br/index.php/revista 
GIRBAL BLACHA, Noemí. Acerca de la Historiografía Agraria Argentina. Espacio regional, sujetos sociales y políticas públicas. En: 3as Jornadas de Historia de la Patagonia. San Carlos de Bariloche, 6 de noviembre del 2008. Colgado en línea: http://www.hechohistorico.com.ar/Trabajos/Jornadas\%20de\%20Bariloche\%20\%202008 /Girbal-Blacha.pdf. Visitado por última vez: Julio del 2012.

. La historia regional argentina en tiempos del Bicentenario de la Revolución de mayo de $1810 . \quad$ Colgado en línea: http://www.memoria.fahce.unlp.edu.ar/art_revistas/pr.4182/pr.4182.pdf. Visitado por última vez: Mayo del 2012.

GRACIANO, Osvaldo; LAZZARO Silvia (compiladores). La Argentina Rural del Siglo XX. Fuentes, problemas y métodos. Buenos Aires: La Colmena, 2007.

LEONI María Silvia. El movimiento intelectual en Resistencia y la construcción del Chaco (1910-1946). Noveno Congreso Nacional y Regional de Historia Argentina. Rosario, 26-28 de septiembre de 1996, Academia Nacional de la Historia, Buenos Aires, 1996.

La Construcción de la Región en la Historiografía chaqueña del siglo XX. La perspectiva de Guido Miranda. Folia Histórica del Nordeste, n. 17, IIGHI-CONICET, Resistencia, 2008.

Una perspectiva sobre la construcción del ciudadano en el Territorio Nacional del Chaco. Diagnostico y propuestas de Juan Ramón Lestani. Revista Pilquen-Sección Ciencias Sociales, Año VII, n. ${ }^{\circ}$ 7, 2005.

MEADER, Ernesto; LEONI, María S; QUIÑONEZ, María G.; SOLIS CARNICER, María del Mar. Visiones del Pasado. Estudios de Historiografía de Corrientes Corrientes: Ediciones Moglia, 2004.

MIRANDA, Guido. Tres Ciclos Chaqueños. Resistencia: Librería La Paz, 2005.

MORADIELLOS, Enrique. Las caras de Clío. Una introducción a la historia, Madrid: Siglo XXI, 2001.

ROFMAN, Alejando B. y ROMERO, Luis A. Sistema socioeconómico y estructura regional en la Argentina. Nueva edición actualizada, segunda edición. Buenos Aires: Amorrortu, 1997.

ROZE Jorge P. Lucha de clases en el Chaco Contemporáneo. Resistencia: Librería La Paz, 2007.

Revista Eletrônica da ANPHLAC, n.14, p. 109-131, jan./jun. 2013. http://revista.anphlac.org.br/index.php/revista 
ROZENVAING, Eduardo. Etnias y arboles. Historia del Universo ecológico Gran Chaco. (2010). Colgado en línea: http://www.historia.ucr.ac.cr/cmelendez/bitstream/123456789/300/1/Etniasyarboles.pdf. Visitado por última vez: Julio del 2012.

SAID, Edward. Representaciones del Intelectual. Buenos Aires: Paidos, 1996.

SCHALLER, Enrique. La colonización en el Territorio Nacional del Chaco en el periodo 1869-1921. Resistencia: Investigaciones del instituto de Geohistória, 1986.

La política de tierras y la colonización en la provincia del Chaco (1870-1990).

Decimo Congreso Nacional y Regional de Historia Argentina. Santa Rosa, 6 al 8 de mayo de 1999.

SCHALLER, Enrique y BORRINI, .La colonización en el Territorio Nacional del Chaco en el Periodo 1916-1930. En: Separata quinto congreso nacional y regional de Historia Argentina. Celebrado en Resistencia y Corrientes del 1 al 5 de septiembre de 1981. Academia Nacional de la Historia. Buenos Aires, 1997.

SLUZTKY, Daniel. Tenencia y distribución de la tierra en la región NEA Investigaciones del instituto de Geohistória. Buenos Aires: CFI, 1974.

VALENZUELA Cristina. Abordajes recientes en torno a la investigación de las economías regionales. El caso del Nordeste Argentino. En: GRACIANO Osvaldo y LAZZARO, Silvia (Comps.) La Argentina Rural del siglo XX. Fuentes, problemas y métodos. Buenos Aires: Colmena, 2007.

Recebido em: julho de 2012 e aprobado em: novembro de 2012.

Revista Eletrônica da ANPHLAC, n.14, p. 109-131, jan./jun. 2013.

http://revista.anphlac.org.br/index.php/revista 